\title{
VICTORIA CAMPS
}

Etica de esperanza

\begin{abstract}
Q UÉ puedo hacer si hago lo que debo?" Kant no pudo concebir una teoría del deber moral sin el colofón de la respuesta a la razón última del mismo: ¿qué puedo esperar? ¿qué razones hay para la esperanza? Razones las hay, nos dirá, si aprendemos a esperar lo debido, lo que no está más allá de nuestras posibilidades. Como la teoría del conocimiento - ¿qué puedo saber?-, la teoría moral kantiana es una teoría del poder y los límites del ser humano. La razón no ordena lo imposible. Por eso la ley moral prescribe "haz aquello mediante lo cual te haces digno de ser feliz". No: "haz aquello que te haga participar de la felicidad", pues en tal caso, el motivo de la razón sería la satisfacción de todas las inclinaciones, un motivo empíri$\mathrm{co}$, incierto, contingente. La razón no tiene por objeto la felicidad, sino la dignidad humana. ¿Qué puedo esperar? "Cada uno tiene motivos para esperar la felicidad exactamente en la medida en que se haya hecho digno de ella."

Cada uno tiene motivos para esperar la felicidad, pero ésta no es una consecuencia necesaria, causada por la moralidad. Para que lo fuera, haría falta el cumplimiento de un requisito adicional: el sistema de moralidad, la unión de felicidad y virtud es una simple idea que descansa "en la condición de que cada uno haga lo que debe, es decir, de que todas las acciones de seres racionales sucedan como si procedieran de una suprema voluntad que comprendiera en sí o bajo sí todas las voluntades privadas". Ni la naturaleza de las cosas ni la causalidad nos hablan del vínculo entre
\end{abstract}


las acciones morales y la felicidad. La ley moral es otra cosa y, además, "obliga a cada uno, en el uso que haga de su libertad, aunque otros no se comporten de acuerdo con esa ley". Sólo la razón suprema tiene el privilegio de ser, al mismo tiempo, voluntad y causa de felicidad. Sólo en un supuesto reino de los fines, la felicidad y la moralidad serán inseparables. ${ }^{1}$

En Kant convergen de una forma genial y sorprendente la fe en el progreso y la conciencia de los límites. Hay respuesta para la esperanza, pero una respuesta que sólo encuentra exacto cumplimiento en la teología. Más acá del reino de los fines, en el mundo fenoménico e inmoral, la aventura moral cuenta con el apoyo de tres supuestos por demás insatisfactorios. Son los siguientes: 1) sé qué debo hacer (el imperativo a priori de la moralidad existe), 2) la unión de felicidad y moralidad dependen de que cada uno haga lo que debe, 3) puedo esperar la felicidad correspondiente a mi dignidad.

Tal vez lo que nos distancie más de Kant sea nuestra incapacidad para mantener idénticos supuestos. Sólo el segundo podemos mantenerlo en los mismos términos: para que el mundo feliz sea un hecho, cada uno debe cumplir su deber. La empresa moral es, por esencia, social, colectiva: estamos obligados a convivir y a entendernos si queremos vivir bien. Las otras dos hipótesis, en cambio, son más qué dudosas: hoy no sabemos qué debemos hacer y desconfiamos de que acabe dándonos la felicidad de que nos hemos hecho merecedores. Veamos ambos puntos por separado.

¿Sabemos qué debemos hacer? ¿Somos capaces de legitímar a priori el orden justo? Notemos, en primer lugar, que Kant no distingue entre el "debo" singular y el "debemos" plural. El imperativo moral lo asume y lo resuelve el individuo,

\footnotetext{
${ }^{1}$ Para todo esto, cf. Kant, Crítica de la razón pura "El canon de la razón pura".
} 
pero lo hace sometiendo su máxima subjetiva a la prueba de la universalidad: debo hacer lo que debiéramos hacer todos, lo que cada uno quisiera ver convertido en ley universal. No hay excepciones para la moral. Y nadie que se precie de tener razón está incapacitado para reconocer el bien. Así, no tiene razón de ser la distinción entre una moral pública y una moral privada con razonamientos diversos: una moral regulada por la conciencia de cada cual, y otra por un supuesto interés colectivo. No tiene sentido, porque, desde la perspectiva de la razón, mi interés y el de cada uno, la voluntad particular y la voiuntad general, han de coincidir. Sólo aquello que vale para todos, ha de valer para mí también, sólo es moralmente prescriptible lo que puede ser dicho públicamente.

Para Kant, el problema no es de conocimiento, sino de voluntad. La razón ve claro qué debe hacer, pero la voluntad se niega a seguirla. Por eso es tan improbable que advenga naturalmente la felicidad. Tendrían que quererlo todos los hombres, y Kant desconfía de esa buena voluntad generalizada.

Pero el supuesto kantiano es falaz. La limitación está tanto en el conocimiento como en la voluntad. El paso del yo al nosotros no es tan fácil. Y no sólo porque los "nosotros" nos fallen, sino porque el yo no es tan sabio ni tan inteligente como Kant presume. Agnes Heller ha hecho ver cómo Kant "disuelve" al individuo en la especie, construyendo así "la única ética democrática consecuente posible en un mundo que... efectivamente está regido por los intereses". En efecto, en el sistema kantiano, "la moral ha de vincularse inexcusablemente con todos, ha de ser comprensible para todos; para acceder a la moral no se necesita ni inclinaciones ni una sabiduría fuera de lo común". ${ }^{2}$ Quizá sea una ética excesivamente democrática en el punto de partida: el individuo no tiene la competencia que Kant le atribuye y no puede constituirse en juez de sí mismo y de la colectividad. 36-37.

${ }^{2}$ Agnes Heller, Crítica de la Ilustración. Península, Barcelona, 1984, pp. 
El optimismo kantiano tiene una doble raíz característica del racionalismo metafísico: el aislamiento del sujeto, y -tal como lo formula Isaiah Berlin- la concepción de que "todas las cosas buenas son compatibles y que, por consiguiente, la libertad, el orden, el conocimiento, la dicha, un futuro cerrado (¿también el abierto?) tienen que ser compatibles y aun quizá envolverse recíprocamente de algún modo sistemático". ${ }^{3}$ Ciertamente, en abstracto, cualquier valor es universalizable pero, en la práctica, todo se vuelve más complejo y los valores se disputan entre sí la primacía. Con el solo imperativo de la publicidad es díficil resolver $a$ priori qué debemos, incluso qué debo, hacer. Porque la moral es un asunto práctico, y la práctica de la libertad, de la igualdad o de la vida no es tan límpida y transparente como parece serlo el enunciado teórico. Si hoy desconfiamos de nuestro conocimiento moral es porque somos conscientes de que ningún individuo, que no roce la locura o el despotismo, puede hablar en nombre de esa razón capaz de universalizar sus máximas subjetivas. Por eso, porque el desconocimiento es un hecho, hemos de desconfiar también de las preferencias y razones del individuo solitario. Aceptar nuestras limitaciones en tal sentido significa aceptar y partir de la democracia, no presuponiendo la igualdad racional -como parece presuponer Kant-, sino partiendo de la insuficiencia racional de todos y de cada uno. Insuficiencia que ha de obligarnos a contar con el otro, a convertir la argumentación subjetiva en diálogo intersubjetivo.

Ahora bien, eso ya está medio dicho por otra teoría moral que viene a corregir el imposible a priori kantiano. Si no hay hombres ilustrados y especialistas capaces de gobernarnos y determinar de antemano por dónde debemos ir todos, habrá que buscar un procedimiento adecuado que vaya legitimando paso a paso nuestras decisiones. Es lo. que propuso el utilitarismo con el cálculo empírico de la mayoría: aquello que todos quieren es lo moralmente preferible. Si nadie puede atribuirse la prerrogativa de hablar en

${ }^{3}$ Isaiah Berlin, Conceptos y categorias, Fondo de Cultura Económica, México, 1983, pp. 317-318. 
nombre de la razón o de la voluntad general, si las voluntades de hecho no coinciden, fiémonos de la voluntad de la mayoría. En ese cálculo pretende apoyarse el régimen democrático.

Contra el utilitarismo como sistema de moralidad tenemos argumentos aun de mayor peso que los esgrimidos contra una moral de principios como la kantiana. El utilitarismo carece de principios y espera que la mayoría los determine. Pero, ¿ocurre así realmente? En las democracias participativas, que son las nuestras, ¿quién es en verdad la mayoría? ¿quién decide en su nombre? Además, las mayorías pueden equivocarse radicalmente. De hecho, se equivocan frustrando con ello la aventura moral de la humanidad. Finalmente, ¿qué ocurre con las minorías? Pues no siempre lo que socialmente es justo y conveniente, es asimismo moralmente justo.

En suma, ni el imperativo de la publicidad ni el cálculo utilitarista nos legitiman de una vez por todas el orden justo. La opción no debe estar, pues, en decidirse por uno u otro sistema de moralidad, puesto que ambos son insuficientes, sino en asumir y partir de la propia insuficiencia de la moral. En lugar de confiar de entrada en los principios o en la regla de la mayoría, desconfiar de ambas cosas, pues la ética está siempre en gestación, se hace y se deshace a sí misma, es más una actitud que un cuerpo de creencias. La ética es puro procedimiento - ha observado con agudeza Elías Díaz: ni las mayorías ni los "derechos morales" nos dan la legitimación última y definitiva, pues ninguno de ambos criterios vale si no cuentan como raíz o como límite con la regla de la libertad. ${ }^{4} \mathrm{Ni}$ los principios ni la mayoría son garantía suficiente de conocimiento moral. Los principios han de ser asumidos e interpretados libremente, y ha de ser asimismo posible decidir contra la mayoría.

Ahora bien, ¿podemos ser libres? ¿qué significa exactamente que la ética está en el procedimiento y no en los resultados?

${ }^{4}$ Elías Díaz, "La justificación de la democracia", Sistema, núm. 66 (mayo de 1985), p. 11. 
La pregunta quiere ser más radical que si fuera la mera expresión de escepticismo frente a la posibilidad del individuo de hacerse oír entre o contra la mayoría, a favor o en contra de unos principios. La pregunta trata de poner en cuestión hasta qué punto podemos seguir manteniendo una idea de libertad y de autonomía heredada de la Ilustración o del racionalismo metafísico: la autonomía del individuo frente al sistema.

Un intento de introducir la regla de la libertad en la misma teoría ética, paliando de tal forma la rigidez de los principios, es el del filósofo analítico R. M. Hare, kantiano convertido al utilitarismo. Consciente de que el imperativo kantiano es o excesivamente laxo o injustamente inflexible, debido a su formalismo, Hare piensa en "actualizarlo" con argumentos utilitarios. Según Hare, la argumentación moral pasa por dos niveles: el nivel de las intuiciones (principios), resultado de la educación o de la experiencia vivida, y un nivel crítico que fuerza a cambiar de actitudes cuando las situaciones también cambian. Tales cambios pueden obligarnos a decir que el pacifismo, por ejemplo, no es aceptable, dada la presencia de rogues (aprovechados) en el mundo político, que pretenden sacar partido de las actitudes pacifistas. Contra lo que tales movimientos tienden a creer, apoyados en una sobrevaloración de las actitudes antiviolentas, el armamentismo nuclear tiene hoy un efecto estabilizador. "Si se pone en cuestión la alianza occidental, cualquier cosa puede ocurrir". Como un partidario más de la política de disuasión, Hare, sin asomo de rubor, llega al extremo de afirmar que el pacifista es hoy la mayor amenaza de guerra nuclear.

Someter las intuiciones al juicio de un pensamiento crítico significa valorar adónde puede llevarnos la obstinación en ciertos principios. Significa, pues, sustituirlos o rectificarlos por una moral de las consecuencias: "los juicios morales deben depender de nuestra valoración de las consecuencias probables de las acciones posibles (los filósofos que pretenden otra cosa son irresponsables y se confunden"). Respecto al desarme nuclear, "lo que todos debemos decidir es qué actitud frente a él y frente a la guerra 
en general nos da mejores oportunidades de supervivencia."

La supervivencia como valor último. Y la supervivencia no como lucha contra las fuerzas de la naturaleza, o contra la escasez, sino contra una invención humana que amenaza con extinguir a la propia humanidad. La llamada a favor de la paz, por sí sola, no es defensa de la vida; lo es, en cambio, esa paz ni buscada ni querida, pero irremediablemente mantenida por miedo a la guerra nuclear.

Ello nos demuestra dos cosas. Primero, que ni los principios ni las intuiciones morales son lo que pensábamos: la panacea para saber por dónde debemos ir. Las situaciones cambian y cambian a la par las actitudes porque el significado de los valores morales se tergiversa de continuo. $\mathrm{O}$ quizá sea porque cuando hacemos teoría pura, cuando no pensamos con la urgencia y perentoriedad de la acción, manejamos un lenguaje de absolutos mitificado y sin valor de uso. Un "lenguaje de vacaciones". Ese lenguaje es el de los imperativos categóricos, el de los derechos humanos, el de las Constituciones políticas. Un lenguaje en el que ingenuamente confiamos como punto de partida o de llegada de la acción moral. Cuando, de hecho, ese lenguaje "actualizado" se encuentra contaminado, lleno de ambigüedades y contradicciones. Ya lo decía Hobbes: las palabras de las cosas que nos afectan son palabras "inconstantes", porque no todos los hombres son igualmente afectados por la misma cosa, ni todos los hombres al mismo tiempo". ${ }^{6} \mathrm{Ni}$ todos utilizamos las palabras con el mismo valor ni las palabras conservan un significado unívoco a lo largo del tiempo.

Pero hay, además, otra cuestión. Hare habla de cambio de las situaciones, pero de hecho, lo que provoca una rectificación de sus primitivas intuiciones es la existencia de rogues, la sospecha, tan temida por Kant, de que no todos

${ }^{5}$ R.M. Hare, "Philosophy and Practice: Some Issues About War and Peace", en Philosophy and Practice, ed. A. Phillips Griffiths, Cambridge University Press, 1985, pp. 1-15.

${ }^{6}$ Hobbes, Leviathan, IV. 
harán lo que deben hacer, con lo cual el sistema de moralidad se verá frustrado. La solución de Kant era clara: cada uno tiene la obligación de cumplir con su deber aun cuando nadie más lo haga. La ética kantiana era imprudente. Pero hay quien cree que la imprudencia es temeridad y no es, por tanto, moral.

Weber compartía aún esa admiración por la pureza ética propia de Kant. Pero sintió más profundamente la escisión que suponía. Por una parte, veía una ética de la convicción, fiel a principios, por otra, la ética de las consecuencias, a la que sintomáticamente llamó "de la responsabilidad", pues si uno actúa sólo por principios, acaba por no poder responder de sus acciones. La distinción era lúcida y sugerente, pero correspondía a tipos ideales de eticidad y de pragmatismo político. Pero ocurre que ni los principios son tan nítidos, ni la ética de las consecuencias merece el nombre de ética. De acuerdo con la división de Weber, el pacifista a ultranza sería el ético, mientras el proarmamentista habría renunciado a sus principios para adaptarse a la situación, a las necesidades, intereses y urgencias del presente.

No es tan sencillo ni tan inequívoco clasificar a las personas o a sus actos. Se suele concebir a la ética como esa instancia que juzga y critica la acción política, desde unos principios, fines o valores absolutos, porque si juzga teniendo sólo en cuenta las consecuencias, la eficacia, acaba confundiéndose con la política. Me pregunto hasta qué punto podemos seguir manteniendo esa concepción de la ética. Ésta, al igual que la política, deben reflexionar sobre el presente. ¿Desde dónde? ¿Sólo desde esos valores intangibles y puros?

Resumamos lo dicho hasta aquí. La conciencia de los límites es, en nuestro caso, más profunda que en Kant, porque afecta no sólo a los límites de la voluntad, sino a los límites del saber. La respuesta teórica al ¿qué debo hacer? choca en la práctica con el conflicto de valores. En teoría sabemos que es mejor la paz que la guerra, la tolerancia que la intolerancia, el amor que el odio, la riqueza que la pobreza, la verdad que la mentira. Pero en la realidad esos absolutos se desvanecen. Ignoramos qué caminos llevan a su 
realización, porque inmediatamente nos damos cuenta de que lo que buscamos, y lo que de veras vale, es el éxito, el dominio sobre los demás, la capacidad de competir, y todo ello al precio que sea. La realidad nos desborda, la sensación de impotencia, de incompetencia y desamparo es total. Sensación que no sólo afecta al individuo con respecto al sistema y a sus instituciones; afecta por igual a éste con respecto ál individuo. De ahí la crisis del Estado del bienestar, que, por un lado, asiste demasiado y, por otro, no puede responder a todas las demandas de la sociedad. De ahí la crisis de instituciones como la familia o la escuela: no pueden ya cumplir las funciones tradicionales, y no encuentran otras funciones que las remplacen. Muchas cosas parecen aguantarse simplemente por inercia, por mor de una supervivencia difícil de justificar. Así, parece como si la única forma de transformar lo que hay fuera empezando de nuevo, olvidándonos de las miserias y las glorias del pasado. Porque la respuesta al ¿qué debo hacer? nos deja siempre insatisfechos. Siempre la apuesta por uno o unos valores, nos fuerza a sacrificar otros valores.

Si a esa limitación añadimos la de la debilidad de la voluntad, la desconfianza en la capacidad moral de los otros. Si prescindimos, además, de la teología como tabla últimamente salvadora, ¿qué cabe esperar de la moral? o, incluso, ¿qué podemos esperar de una política moralmente orientada? O la ética es una mera instancia crítica que razona a partir de negar y rechazar lo que hay, o es algo más. Pues la mera crítica acabaría desvaneciéndose si no contara con soporte alguno. Pero, ¿qué más podemos esperar de la ética? ¿qué podemos esperar de la libertad?

\section{II}

Sin esperanza no hay ética posible si concebimos la ética como un proyecto de vida y sociedad mejores. La esperanza debe ser mantenida a toda costa, pero no necesariamente ha de configurarse siempre de la misma manera y en torno a idénticos objetivos. Kant confiaba en la realización del 
sistema de moralidad, la definitiva reconciliación en un reino de los fines, un mundo justo donde la felicidad y el mérito coincidieran. Pues bien, ese final feliz no es el objeto de nuestra esperanza. Comparto la opinión de Carlos Thiebaut cuando, a propósito del progreso moral, advierte que "el ideal de progreso moral es necesariamente ensoñado y necesariamente impensable en los términos en que nos fue transmitido", esto es, en términos de armonía, reconciliación y salvación total. ${ }^{7}$

Es una convicción en torno a la cual da vueltas el pensamiento de Horkheimer con constancia y lucidez. La idea del hombre ha cambiado, nos dice, y ya no marcha paralela a una teoría de la razón. "La palabra 'hombre' ya no expresa el poder del sujeto capaz de resistir el statu quo, por mucho que pese sobre él". El individuo ya no es el individuo: sólo es real como parte del todo al que pertenece. Un todo frente al que, por otra parte, se siente ajeno, un todo incontrolable. Esa segunda naturaleza que Rousseau veía en el ser social plenamente logrado, esa sociedad racional que Kant aún podía imaginar, son ya impensables. Hemos abandonado la creencia en la posibilidad de un mundo justo. Por lo menos, mientras se mantenga esa situación de desamparo y de impotencia ante un todo social y político que nos engulle y nos absorbe. ${ }^{8}$

Horkheimer comparte y recuerda con nostalgia la convicción kantiana de que "lo divino de nuestra alma es su capacidad para las ideas". Esas ideas deberían ser las reguladoras de la práctica. Pero ya hemos visto que las ideas, entran en conflicto entre sí, y, en tal caso, empiezan a perder valor primigenio y cambian de sentido. Si la idea de hombre ha cambiado, si el individuo ha dejado de serlo y ya no es capaz de aislarse para distinguir, desde la perspicacia de su razón, el bien y el mal, también tiene que cambiar la concepción de la ética en tanto configuradora de la acción humana, sea ésta de carácter social, político o privado.

7 Carlos Thiebaut, "Progreso moral y pesimismo", en prensa.

${ }^{8}$ M. Horkheimer, "The Concept of Man", en Critique of Instrumental Reason, Continuum, Nueva York, 1974, p. 4. 
Durante una porción de siglos, la ética ha estado determinada y formada por la religión, por la creencia en uno o varios dioses. La tarea de una ética sin religión es relativamente reciente, acaba de empezar, como quien dice, y está casi todo por hacer. ${ }^{9}$ A mi modo de ver, mientras esa ética siga fiel a los paradigmas religiosos - trascendentes o trascendentales, salvíficos-, navegará entre dos aguas sin encontrar su propio cauce. Aristóteles ya vio que las ideas platónicas no podían ser el fin buscado por la ética. La ética busca el fin y el bien de los seres humanos, que no son dioses. La vida contemplativa, armónica y reconciliada es, sin duda, perfecta, pero es una forma de vida divina, un bienestar sobrehumano. El objetivo de la ética no puede ser teorizar sobre esa vida ni tratar de llegar a ella. El objetivo de la ética es pensar el conflicto y la escisión, no tanto para superarlos, como para tomar conciencia de ellos y evitar, así, que el individuo acabe de sucumbir en sus manos.

Pero queda aún en pie la pregunta inicial: ¿se justifica de este modo la ética? ¿es aún mantenible la esperanza?

Parecen dos preguntas, pero no lo son. Si el objetivo de la esperanza no es un mundo feliz, la esperanza de la ética estará en la práctica ética misma. La desesperanza en la salvación definitiva no tiene por qué teñir de escepticismo o nihilismo la aventura ética. No es cierto que no vayamos ni queramos ir a ninguna parte. No es cierto tampoco que, vayamos a donde vayamos, nos da lo mismo. El relativismo, como la opinión de que cualquier creencia es tan buena como cualquier otra, no es mantenido concienzudamente por nadie. ${ }^{10}$

El supuesto de la ética (supuesto indemostrable, como cualquier punto de partida) es que el ser humano es proyecto, que hace y configura su existencia. $Y$ ese quehacer como tal tiene ya sentido, no precisa de ulteriores explicaciones.

Lo importante es que el quehacer no se frustre ni pierda

9 Cf. Dereck Parfit en Reasons and Persons, Clarendon Press, Oxford, 1984, pp. 453-454.

10 Richard Rorty, "Pragmatism, Relativism, and Irrationalism", en Consequences of Pragmatism, University of Minnesota Press, 1982, p. 166. 
ese su sentido ético. Para lo cual la reflexión no consistirá en fijar unos ideales a los que debe ajustarse una realidad social y política que discurre por otro camino independiente de ellos. La ética, reflexión sobre el presente, ha de procurar preservar todos los valores del presente: esos valores que parecen no poder convivir todos juntos. Me atrevería a decir que el conflicto moral es siempre un conflicto entre la libertad y cualquier otro valor: la igualdad, la paz, la supervivencia, la fidelidad. Cuidar de que la libertad no sucumba, antes se ejerza en todo momento es el meollo del proyecto ético. ${ }^{11}$

Pero decíamos que el individuo no se encuentra a sí mismo, que ese reducto de la razón desde la que pensar la libertad es falaz. La ética es proyecto, pero no proyecto individual, sino colectivo. Y la colectividad es la que decide y determina el curso del proyecto. Si el proyecto es colectivo y, además, hay que irlo determinando sobre la marcha, no podemos partir de un ¿qué debo hacer? singular, ni aun cuando la prueba del deber sea la universalidad. Hay que partir del ¿qué debemos hacer?, decidido colectivamente, dialógicamente. Lo ético no son los resultados, o no lo son únicamente: la ética está también y sobre todo en el procedimiento. Pensemos en el proyecto democrático. Las democracias que conocemos no nos satisfacen, no tenemos tampoco un ideal de democracia claro, pero sabemos que la mejor forma de gobierno es la democrática. ¿Por qué? Porque, por lo menos, cuenta con un modo de proceder justo, su punto de partida no es petulante, sino asume todas las deficiencias y limitaciones del conocimiento humano. Es un régimen cimentado sobre el diálogo y la discusión previos a la deliberación y a la decisión. Si asumimos nuestra ignorancia e impotencia para imaginar la sociedad justa, o para decidir cómo llegar a ella, si desconfiamos, con Kant, de que cada uno haga lo que debe hacer, ¿qué remedio nos queda más que confiar en nuestra capacidad de comunica-

1 Eusebio Fernández ha visto perfectamente el conflicto a que me retıero cuando define la justicia como "la relación correcta entre la libertad y la igualdad". Cf. "El contracte i els drets morals", Saber, núm. 4 (julio/agosto 1985), pp. $38-41$. 
ción y en el intercambio de opiniones? Como ha visto el pensamiento hermenéutico, ninguna realidad puede ser aprehendida en su totalidad, ni ser agotada en el concepto. El fenómeno de la comprensión, que es linguístico, es circular: el círculo entre lo comprendido y el que comprende, y ese círculo constituye la universalidad. Lo cual quiere decir que no hay comprensión sin diálogo, aun cuando éste sea diálogo consigo mismo. (H.G. Gadamer).

No es función de la filosofía encontrar soluciones, sino dar nombres, descubrir diferencias y paradojas. Horkheimer se ha referido largamente a la ambivalencia de la libertad; una vez convertida en regla de conducta puede dar paso a lo opuesto a ella: la automatización de la sociedad y el comportamiento, la abolición de las relaciones personales donde la libertad encuentra su expresión primaria. El desarrollo e innovación científicos y técnicos poseen a la vez el poder de liberar y oprimir. La misión del pensador es denunciar esos peligros o celebrar las ocasiones de progreso. Ninguna filosofía - ha dicho Gadamer- va a resolver los problemas de la sociedad o de la política. Sucumbir a la tentación del profeta conduce al dogmatismo o al terror. Pero sí es posible favorecer las condiciones de diálogo: la solidaridad, la comunidad deberían ser los fines de nuestra práctica. Aristóteles pudo efectuar fácilmente la transición de la ética a la política porque su política "presupone los resultados de la Ética: primero y sobre todo una conciencia normativa común y compartida". Hoy carecemos de esa unanimidad en el saber. Por eso, la transición de la ética a la política ha de ser otra cosa. En cualquier caso, "la filosofía práctica insiste en la función de guía de la phrónesis, que no propone ninguna ética nueva, sino más bien clarifica y concretiza los contenidos normativos existentes". ${ }^{12}$

La ética viene a sustituir a la religión. La esperanza ética es religiosa en un sentido diverso del tradicional. No es esperanza en una trascendencia última y duradera, ni si-

12 H. G. Gadamer, en R. Bernstein. Bevond Objectivism and Relativism, University of Pennsylvania Press, 1983, "A Letter of Professor Hans-Georg Gadamer", pp. 262-263. 
quiera la obstinada esperanza blochiana en la utopía intrahistórica. Es esperanza en la persistencia y perseverancia del mismo proyecto ético. ¿Con qué fundamento? La creencia de que el ser humano es proyecto. ¿Proyecto progresivo? La historia nos habla de un cierto progreso moral, pero también de espantosos regresos. El futuro parece escapársenos. Si, a pesar de todo, pervive la esperanza, es decir, pervive la voluntad de proyecto, o pervive la tensión con nuestro entorno, tenemos que reconocer que el fundamento es religioso.

Septiembre de 1985 